\title{
Student Perspectives on Using Clickers in Upper-division Physics Courses
}

\author{
Katherine K. Perkins ${ }^{1,2}$ and Chandra Turpen ${ }^{2}$ \\ ${ }^{1}$ Science Education Initiative, University of Colorado, Boulder, CO 80309 \\ ${ }^{2}$ Department of Physics, University of Colorado, Boulder, CO 80309
}

\begin{abstract}
A growing number of faculty are using clicker questions and peer instruction in introductory physics courses at institutions across the US; however, this approach is rarely used in upper-division physics courses. At the University of Colorado at Boulder (CU), faculty have been incorporating clicker questions in upper-division courses since $2004-$ clickers have now been used 24 times in 10 different upper-division courses by 14 different faculty. We surveyed students in 16 of these classes (including 2 classes of a graduate course), soliciting their perspectives on and recommendations for using clickers in upper-division courses. We find that $77 \%$ of the students recommend using clickers at this level. In all classes, a majority of students favor clickers and there are few negative responses. Through analysis of students' responses, we identify what they value about the use of clickers and the perceived mechanisms by which clickers support their learning. Finally, we find broad student agreement on how to best implement clickers in these courses (i.e. 2-5 challenging conceptual questions interspersed with lecture where peer instruction is encouraged). For upper-division clicker questions used at CU, see: http://www.colorado.edu/physics/EducationIssues/cts/index.htm.
\end{abstract}

Keywords: clickers, personal response systems, student opinion, undergraduate, graduate, upper-division, physics major PACS: 01.30.lb, 01.40.Di, 01.40.Fk, 01.40.gb, 01.50.-i

\section{INTRODUCTION}

Clicker technology and the pedagogy that it supports - concept tests and peer instruction - are now frequently used in introductory physics courses as an effective way to engage students during lecture. A growing body of research shows that, in large-lecture, introductory courses, students generally enjoy this teaching approach, find it useful for their learning, and learn more as measured by conceptual assessments [1]

Despite these successes in lower-division courses, few faculty use clicker questions and peer instruction in upper-division courses, and the introduction of these interactive engagement techniques into these majors' courses has not been well studied. Across the sciences, only a few research studies on clickers have included upper-division courses [2], with none in physics. However, research on student learning in upperdivision courses has documented significant student conceptual difficulties in all of the core courses for physics majors [3] and compels us to reconsider how we teach upper-division physics students.

Clicker questions and peer instruction can be an appealing option for faculty wanting an effective means of incorporating interactive engagement into the traditional course structure, rather than attempting any radical restructure of the curriculum. Faculty at CU-Boulder have increasingly chosen to use clickers and peer instruction in the upper-division courses. Clickers have been used in a total of 24 upper-division classes - 10 different courses by 14 different faculty members (12 non-PER and 2 PER).

While there are many factors to consider when choosing whether to adopt a new teaching approach, two important ones are 1) the students' response and 2 ) the impact on student learning. The positive impact of using clickers and other interactive engagement techniques on student learning in upper-division courses at CU is reported elsewhere [4]. In this paper, we focus on the first factor by probing student opinions about and recommendations for using clickers in a range of upper-division physics courses and one graduate course. It is important to note that student opinions about clickers will depend on how clickers are implemented in class [5]. In all of these upper-division courses, clicker use has included challenging conceptual questions and peer instruction.

We find that students who have experience using clickers in these courses consistently and overwhelmingly prefer lecture with clickers and recommend its use in upper-division courses. We examine their perceptions of how and why using 
TABLE 1. Survey results for upper-division physics courses using clickers

\begin{tabular}{|c|c|c|c|c|c|}
\hline \multirow{2}{*}{ Course } & \multirow{2}{*}{ Instructor } & \multirow{2}{*}{$\begin{array}{c}\text { \# of students } \\
\text { enrolled }\end{array}$} & \multirow{2}{*}{$\begin{array}{c}\text { Responses* } \\
\#(\%)\end{array}$} & \multicolumn{2}{|c|}{ \% who prefer lecture } \\
\hline & & & & with clickers & without clickers \\
\hline Mechanics/Math Methods I & non-PER & 39 & $29(74 \%)$ & $86 \%$ & $7 \%$ \\
\hline Mechanics/Math Methods II & non-PER & 27 & $23(85 \%)$ & $78 \%$ & $13 \%$ \\
\hline EM I & PER & 27 & $21(78 \%)$ & $81 \%$ & $10 \%$ \\
\hline EM I & PER \& non-PER & 59 & $46(78 \%)$ & $86 \%$ & $2 \%$ \\
\hline EM I & non-PER & 38 & $33(87 \%)$ & $82 \%$ & $6 \%$ \\
\hline EM II & non-PER & 48 & $41(85 \%)$ & $83 \%$ & $2 \%$ \\
\hline QM I & PER & 37 & $30(81 \%)$ & $77 \%$ & $10 \%$ \\
\hline QM I & PER \& non-PER & 32 & $30(94 \%)$ & $90 \%$ & $7 \%$ \\
\hline QM I & non-PER & 49 & $45(92 \%)$ & $91 \%$ & $7 \%$ \\
\hline QM II & non-PER & 20 & $15(75 \%)$ & $73 \%$ & $7 \%$ \\
\hline Solid State & non-PER & 10 & $6(60 \%)$ & $67 \%$ & $17 \%$ \\
\hline Solid State & non-PER & 13 & $11(85 \%)$ & $64 \%$ & $9 \%$ \\
\hline Stat Mech & non-PER & 18 & $16(89 \%)$ & $81 \%$ & $0 \%$ \\
\hline Stat Mech & non-PER & 33 & $21(64 \%)$ & $58 \%$ & $5 \%$ \\
\hline Grad AMO & 2 non-PER & 23 & $21(91 \%)$ & $76 \%$ & $5 \%$ \\
\hline Grad AMO & non-PER & 15 & $12(80 \%)$ & $100 \%$ & $0 \%$ \\
\hline Total & & 488 & $400(82 \%)$ & $82 \%$ & $6 \%$ \\
\hline \multicolumn{3}{|l|}{ Total Unique Students\$ } & 234 & $82 \%$ & $6 \%$ \\
\hline
\end{tabular}

clickers impacts their learning, including their perspectives on the role of peer discussion. Finally, we report on students' preferred implementation practices which can serve as a useful guide for faculty interested in incorporating clickers into their upper-division courses.

\section{DATA COLLECTION}

Between Fall 2006 and Spring 2009, we surveyed students in 16 upper-division classes using clickers, including 2 graduate classes, as summarized in Table 1 . We aimed to capture the range of opinions among students at CU by including a variety of courses and faculty (9 different clicker courses and 10 different faculty). Six out of 10 faculty had prior experience using clickers in lower-division courses before incorporating clickers into their upper-division courses. For the other 4, this was their first experience using clickers, but all 4 of these faculty were supported by the PER group to some degree - from minor consultation to team teaching with a PER member. Faculty implementation of clickers was broadly similar across these courses. The clicker questions included challenging conceptual questions (the development of questions in Mechanics and Math Methods, QMI, EMII, and Stat Mech was done by or supported by PER faculty), and all faculty allowed for peer instruction in the classroom. However, there were variations in the number of questions per lecture, the extent to which faculty encouraged peer instruction and the approaches used in the follow-up discussion.
The end-of-term surveys probed students' opinions about various aspects of the course (lecture, clicker questions, homework, etc.) using a mix of multiplechoice and short answer questions [6]. We administered the surveys online over the last two weeks of the course with response rates greater than $75 \%$ for most courses. Many students took several of these courses over this time period. Among the 400 responses we collected in these courses, there are 234 unique students. Here we report results for all 400 compiled responses since implementation across the courses is not identical and could impact student opinion; however, in Table 1, we see no differences in the percent preferring clickers with lecture whether using all responses or compiling multiple responses into unique-student responses.

On all surveys, we asked the following question: "For the clicker questions and discussion in this course, please explain why you felt they were particularly useful or not useful for your learning." We coded 70 of the responses from unique students, categorizing students' reasons for why clickers did or did not support student learning. The 70 responses were distributed across the 16 courses and included students preferring clickers and preferring no clickers.

\section{ANALYSIS AND DISCUSSION}

Students recommend clickers ("clickers" here and throughout means "clickers with challenging conceptual questions and peer instruction"): After experiencing an upper-division course taught using 
clickers, students are remarkably consistent in their preference for lecture with clickers. When asked to directly compare pure lecture with no clickers to lecture with clickers (Figure 1), 82\% of students responded that lecture with clickers is more or much more useful for learning than pure lecture. Of the remaining students, most are neutral with only $6 \%$ of students rating pure lecture as more useful. In Table 1, we see that for all classes - regardless of instructor, class size, content, quality of clicker questions, or minor variations in implementation - a majority of students preferred lecture with clickers over pure lecture. In addition to finding clickers beneficial for their learning, students also enjoy using them; 81\% reported that they like or strongly like using clickers.

Given this preference for lecture with clickers, it is not surprising that a total of $77 \%$ of students in these clicker courses recommend (32\%) or highly recommend (46\%) using clickers in upper-division courses (defined as sophomore level mechanics and math methods or higher). Only $8 \%$ of students do not recommend using clickers. Comparatively, $81 \%$ of students in CU's introductory calc-based physics courses recommend using clickers in those classes. While CU undergraduates have extensive experience with clickers in the introductory courses and may be arguably more inclined to appreciate the benefits of clickers, we find that the graduate students who come to CU from a wide variety of schools are also equally consistent in their opinion $-85 \%$ of these students prefer lecture with clickers even in this small $(<25$ students) graduate course on AMO physics.

Student-cited benefits of clickers: We used students' short answer responses to examine their reasons for why clickers were or were not useful for their learning. While clickers are a tool that - if used well - can help instructors create an in-class environment that aligns with the principles of how people learn [7], we wanted to examine whether students' perceptions of the pedagogical benefits of clickers are consistent with this research.

Table 2 summarizes the most commonly-cited benefits and criticisms of using clickers among the 70

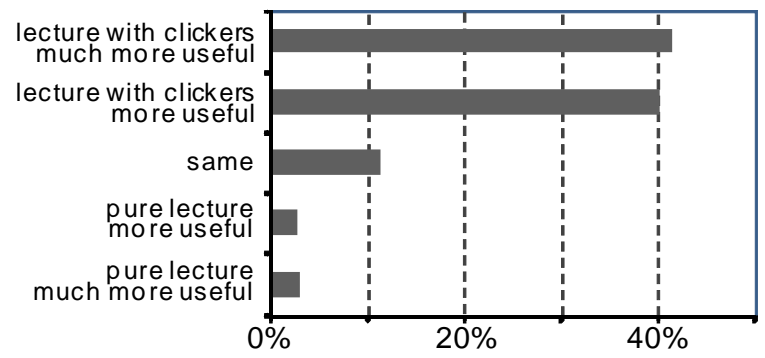

FIGURE 1. Student ratings of lecture with clickers vs pure lecture. $82 \%$ of students rate lecture with clickers as more or much more useful for their learning than pure lecture presentation. $(\mathrm{N}=395)$ student responses that were coded. Overall, 64 students made one or more positive comment and 9 students made one or more negative comment. Statements could be coded into multiple categories or sub-categories, as appropriate. Due to lack of space, here we focus only on the benefits..

Many students cited some improved mastery (code A, 50\%). While most responses under this code were general, such as improving or solidifying understanding, some student responses related to intuition ("a great way to develop intuition"), to multiple perspectives, reasonings, or approaches ("They were good for looking at problems from various perspectives.”), and to sorting out confusions or subtleties in the physics ("...brought up some subtle points I would have otherwise missed.”). Another common theme was comments about the nature of the questions or activity (code B, 44\%) - keying in on the conceptual focus (31\%), the challenging nature of the questions (14\%), or the application of ideas (4\%).

The five other dominant reasons (codes $\mathrm{C}-\mathrm{G}$ ) given by students can be classified broadly as related to changes in the classroom environment. These provide insight into the mechanisms that students see as leading to their improved mastery associated with clicker use.

Most students (63\%) focused on how clickers made or allowed them to be active in some way (code C): thinking or digesting (17\%); applying, using, or practicing (11\%); discussing or talking $(24 \%)^{1}$; checking or testing (7\%); or sorting out ideas (14\%). Students also mentioned timing aspects of clickers (code D, 26\%) - with most positive either about the time to think (9\%) or the immediacy of being able to think about what was just covered in lecture (19\%).

The opportunity to discuss with others (code E,

TABLE 2. Common categories of why clickers help or not

\begin{tabular}{|l|c|c|}
\hline \multicolumn{1}{|c|}{ Code } & $\begin{array}{c}\text { \# of responses* } \\
\text { (out of 70) }\end{array}$ & \% \\
\hline \multicolumn{1}{|c|}{ Positives } & 64 & $91 \%$ \\
\hline A. Improved mastery & 35 & $50 \%$ \\
\hline B. Focus of Activity & 31 & $44 \%$ \\
\hline C. Active processing/activity & 44 & $63 \%$ \\
\hline D. Time/pause to think, OR & 18 & $26 \%$ \\
\hline \multicolumn{1}{|c|}{ Immediacy } & 20 & $29 \%$ \\
\hline E. Discussion with others & 20 & $29 \%$ \\
\hline F. Feedback to students & 16 & $23 \%$ \\
\hline G. Engagement & 9 & $13 \%$ \\
\hline Waste of Time/Unnecessary & 7 & $10 \%$ \\
\hline Inappropriate Timing/Premature & 3 & $4 \%$ \\
\hline Reduced Mastery & 1 & $1 \%$ \\
Babying/Too much hand holding & 1 & $1 \%$ \\
\hline
\end{tabular}

*Responses can be coded into multiple categories.

\footnotetext{
${ }^{1}$ To be coded in this category, the wording had to be active, e.g. "it allowed me to talk" as opposed to passive "student discussion”.
} 
TABLE 3: Student recommendations for clicker use

\begin{tabular}{|c|c|}
\hline $\begin{array}{l}\text { Implementation } \\
\text { Factor }\end{array}$ & Student recommendation* \\
\hline $\begin{array}{c}\text { \# of } \\
\text { Questions/Lecture }\end{array}$ & $\begin{array}{l}2-3 \text { questions (62\%) } \\
4-5+\text { questions }(21 \%)\end{array}$ \\
\hline Timing of Questions & Interspersed with lecture (87\%) \\
\hline Peer-discussion & Allow and encourage (80\%) \\
\hline $\begin{array}{l}\text { Preferences about } \\
\text { response mode }\end{array}$ & $\begin{array}{c}\text { 93\% desire peer discussion } \\
64 \% \text { desire individual thinking time }\end{array}$ \\
\hline Question difficulty & $\begin{array}{c}\text { Questions requiring substantive } \\
\text { thinking/debating (61\%) }\end{array}$ \\
\hline $\begin{array}{l}\text { Most useful } \\
\text { question type }\end{array}$ & Challenging conceptual questions $^{\$}$ \\
\hline
\end{tabular}

$29 \%$ ) was explicitly cited as a benefit by students, with many students specifically identifying discussion with peers. One student writes: "I got custom feedback from my peers when I didn't understand something." The broader theme of feedback was mentioned a number of times (code F, 29\%). Of these students, many students mentioned that clickers were a "good check" or "test" of their understanding (17\%), or allowed them to catch mistakes (7\%) or "monitor their understanding" (4\%). Finally, many students explicitly noted that the clickers helped them "pay attention" and/or kept them more "engaged" in the class (code G, $23 \%$ ), literally using these words.

Many key principles of how people learn [7] are represented in these student perceptions, including: engagement, active processing, testing, monitoring and correcting understanding, immediate feedback, and conceptual understanding and reasoning.

Students' recommendations for clicker use: In Table 3, we summarize students' recommendations for clicker implementation - recommendations which we find are generally consistent with how people learn, and support the factors that students cite as helpful for their learning.

Students recommend interspersing about 3 clicker questions per lecture which will allow them time to process and apply the ideas as the lecture proceeds. The vast majority (80\%) recommend that faculty actively encourage peer-discussion. Students differed in their preferences for structuring response collection, choosing either question/peer-discussion/vote (30\%), question/individual vote/peer discussion/revote (18\%), or the hybrid question/individual thinking/peer discussion/vote (45\%). It is notable that $64 \%$ of students desired some time to think about the question before discussing with peers and that $93 \%$ wanted time for peer discussion.

Students recommend challenging conceptual questions. In response to "recommendations regarding target level for most clicker questions”, only $2 \%$ of students voted for easy, straight-forward questions. Of the remaining responses, $61 \%$ of responses recommended the two highest difficulty levels: "Questions where I have to think pretty hard or debate with my neighbor, but can then usually figure out the right answer" (47\%) and "Questions where I have to think hard or debate with my neighbor, and may or may not figure out the right answer" (14\%). 37\% of students preferred more moderate difficulty. Not surprisingly, challenging conceptual questions were viewed as substantially more useful for learning than recall or plug-and-chug questions.

\section{CONCLUSIONS}

These student survey results provide useful advice and encouraging outcomes for faculty members who are considering clicker use in upper-division courses. They suggest that faculty should focus their implementation efforts on designing challenging clicker questions that address learning goals and on fostering student discussion. As a caveat, we again note that most of these students had experience using clickers in lower division courses. For faculty wishing to implement clickers and peer instruction in departments where this approach is not the norm, there are several useful guides for implementing clickers successfully [8].

\section{ACKNOWLEDGMENTS}

We thank the physics faculty who supported this survey work, and the PER@CU group for useful discussions. This work is funded by the CU Science Education Initiative and NSF-CCLI Grant \#0737118.

\section{REFERENCES}

1. See review article and refs therein: Caldwell, J.E. (2007). Clickers in the large classroom: Current research and bestpractice tips. CBE-Life Sci. Educ., 6(1), 9-20.

2. e.g. Preszler, R., Dawe, A., Shuster, C. B., and Shuster, M. (2007). CBE-Life Sci. Educ., 6, 29-41.; Knight, J. K., and Wood, W. B. (2005). Cell Biol. Educ. 4, 298-310.

3. e.g. C. Singh, 2006 PERC Proceedings, (AIP Press, Melville, NY, 2007). C. Manogue et al., Am. J. Phys., 74, 344-350 (2006).

4. Chasteen, S. and S. Pollock. submitted to the 2009 PERC proceedings.

5. Keller, C et al. 2007 PERC Proceedings (AIP Press, Melville NY, 2008).

6. http://per.colorado.edu/surveys/clickersurvey.html

7. Bransford, J., Brown, A., Cocking, R. (Eds) (2000). How People Learn: Brain, Mind, Experience, and School, National Academy Press, Washington, DC.

8. http://STEMclickers.colorado.edu 